\title{
Erratum to: Polymorphic phase transition in Superhydrous Phase B
}

\author{
M. Koch-Müller $\cdot$ P. Dera $\cdot$ Y. Fei $\cdot$ H. Hellwig $\cdot$ \\ Z. Liu $\cdot$ J. Van Orman $\cdot$ R. Wirth
}

Published online: 1 August 2014

(C) Springer-Verlag Berlin Heidelberg 2014

\section{Erratum to: Phys Chem Minerals (2005) 32: 349-361}

\section{DOI 10.1007/s00269-005-0007-4}

The original publication of the article reported polarized FTIR spectra taken on oriented superhydrous phase B crystals. Unfortunately, the authors mixed up the crystallographic $c$ - and $a$-axes during their measurement. The atomic coordinates for hydrogen $\mathrm{H} 2$ should be $x=0.45$; $y=0.18 ; z=0.27$. Thus, spectra in Fig. 10a are taken on the (001) plane with $E$ parallel $b\left(0^{\circ}\right)$ and spectra in Fig. $10 \mathrm{~b}$ are taken on the (010) plane with $E$ parallel $c\left(0^{\circ}\right)$.

The online version of the original article can be found under doi:10.1007/s00269-005-0007-4.

M. Koch-Müller $(\bowtie) \cdot R$. Wirth

Department 4, Telegrafenberg, GeoForschungsZentrum

Potsdam, 14473 Potsdam, Germany

e-mail: mkoch@gfz-potsdam.de

P. Dera $\cdot$ Y. Fei $\cdot$ Z. Liu

Geophysical Laboratory, Carnegie Institution of Washington,

5251 Broad Branch Road NW, Washington, DC 20015, USA

H. Hellwig

Department of Geology, University of Illinois

at Urbana-Champaign, Urbana, IL 61801, USA

J. Van Orman

Department of Geological Sciences, Case Western Reserve

University, Cleveland, OH 44106, USA 